\title{
Theoretical Device Engineering for High-Performance Perovskite Solar Cells Using CuSCN as Hole Transport Material Boost the Efficiency Above 25\%
}

Syed Zulqarnain Haider, Hafeez Anwar* and Mingqing Wang

\author{
S. Z. Haider, Dr. H. Anwar, \\ Department of Physics, University of Agriculture Faisalabad-38040 Pakistan \\ Dr. M. Wang \\ Institute for Materials Discovery, University College of London United Kingdom \\ E-mail: hafeez.anwar@gmail.com
}

\begin{abstract}
Recently, perovskite solar cells (PSCs) have achieved remarkable power conversion efficiency (PCE) about 22.6\%. While most of the hole transport materials (HTMs) used in PSCs are organic in nature with an issue of instability and high cost. In this paper, copper thiocyanate (CuSCN), a low cost inorganic HTM with excellent thermal and moisture stability, is applied as HTM for perovskite solar cells. The device modelling of PSCs is based on the device structure of $\mathrm{FTO} / \mathrm{TiO}_{2} / \mathrm{MAPbI}_{3} / \mathrm{CuSCN} / \mathrm{Au}$. Two interface defect layers, IDL1 as ETM/absorber interface and IDL2 as absorber/HTM interface, are introduced into the device model in order to study the impact of interface quality on the performance of PSCs. Among all of the parameters, defect density and conduction band offset $(\mathrm{CBO})$ at $\mathrm{ETM} /$ absorber interface together with the defect density of absorber influence the device performance appreciably. Upon optimization of all of the parameters, PCE of the device approaches to $25.02 \%$, which is very encouraging. The result shows that leadbased PSC with CuSCN as HTM is an efficient system due to its enhanced hole transport, high electric conductivity and improved chemical interaction with absorber. Further, defect density of ETM/absorber interface and absorber layer could be reduced by optimized deposition process.
\end{abstract}

Keywords: Perovskite solar cells, inorganic HTM, device modelling, interface defect layers, copper thiocyanate 


\section{Introduction}

In recent years, organometallic halide based hybrid PSCs have drawn significant interest of research community due to their excellent optical and electronic properties, high power conversion effi ciency (PCE) and lower manufacturing cost. The PCE of PSCs has got significant boost from $3.8 \%$ in $2009^{[1]}$ to almost $22 \%$ in $2017 .{ }^{[2]}$ In typical PSCs, absorber material is sandwiched between ETM and HTM in order to transport photo induced electrons and holes from light sensitive absorber material to respective electrodes. The most commonly used ETMs are n-type semiconductors including $\mathrm{TiO}_{2}, \mathrm{ZnO}$ and $\mathrm{PCBM}^{[3-6]}$ while organic p-type polymers including spiro-MeOTAD, PTAA, P3HT and PEDOT: PSS are most commonly used HTMs. ${ }^{[5,7-9]}$ HTM has critical role in the transport of holes to the back metal contact. A good HTM should have properties such as i) valence band minimum (VBM) is marginally higher the VBM of absorber for efficient transport of holes as VBM represents the highest occupied electronic states in the material. The difference of VBMs of HTM and absorber at the interface is valence band offset (VBO). ii) Charge carrier mobility should be reasonable $\left(\sim 10^{-2} \mathrm{~cm}^{2} / \mathrm{Vs}\right)$ for quick transfer of holes to counter electrode. iii) HTM should have better photochemical, thermal and moisture stability iv) HTM should be fairly solution processable but should not destroy the underneath absorber layer v) HTM should have good film forming capability in order to fill the pores in absorber layer, thus, making an excellent contact with absorber for enhancing the hole transfer. vi) It must have low crystallization nature for making smooth interface layer in favor of efficient charge flow. vii) HTM should be cost effective, environment friendly, easy to synthesize, low toxic and recyclable. Currently organic HTMs are considered to have high efficiency which are due to different dopants used in them. These dopants also have disadvantages regarding the stability of the device in moisture. For example, spiro-MeOTAD, has two dopants 4-tert-Butylpyridine (TBP) and lithium bis(trifluoromethanesulfonyl)imide (Li-TFSI) which lead towards instability of PSCs in moisture. The overall instability in PSCs ${ }^{[10]}$ is caused by the degradation of the absorber layer due to moisture 
penetration, poor interface between hybrid layers and degradation of individual deposited layers, especially HTMs. In addition, multiple purification processes and preparation methods make the organic HTMs very expensive. ${ }^{[1]}$ PCE of the PSCs increased from $6 \%^{[12]}$ to more than $20 \%{ }^{[13]}$ with spiro-MeOTAD as HTM, but performance deteriorated due to poor stability towards moisture and oxygen and lost $80 \%$ initial PCE after 10 days. ${ }^{[14]}$ PSCs has attained PCE from $3.9 \%{ }^{[15]}$ to $18.1 \%{ }^{[16]}$ with PEDOT: PSS as HTM, but performance degraded and lost 73\% initial PCE after 14 days. ${ }^{[17]}$ Hygroscopic nature of PEDOT: PSS leads towards poor chemical stability, thus, extra layer is required to block the electrons for better performance. In addition, acidic nature of PEDOT: PSS corrodes the substrates. ${ }^{[18]}$ When composite of P3HT and single walled carbon nanotubes (SWNTs) was used as HTM, PCE increased from $6.45 \%^{[19]}$ to $15.3 \%$ and retained $95 \%$ initial PCE after 60 seconds on thermal stressing. ${ }^{[20]}$ Moreover, transport of holes was degraded due to blocking layer between P3HT and back metal contact and this degradation in PSCs, with P3HT as HTM, was controlled by using an additive poly methyl methacrylate (PMMA). ${ }^{[21]}$ PCE of PSCs with PTAA as HTM is increased from 12 $\%^{[22]}$ to $20.2 \%^{[23]}$ and $\mathrm{PCE}$ is retained $95 \%$ of initial value after 20 days, exhibiting the good performance than PEDOT: PSS. ${ }^{[2]}$ High PCE of PSCs are only guaranteed using organic HTMs with the aid of external doping which make PSCs more susceptible to degradation over time under humidity. Therefore, researchers started to use inorganic HTMs instead of organic HTMs and found encouraging results. For example, PSCs with CuI as HTM lost only $10 \%$ its initial PCE in 14 days when stored in air ${ }^{[17]}$ and lost only $8 \%$ of its initial PCE after 90 days under storage in dark. ${ }^{[25]}$ PSC's with $\mathrm{Cu}_{2} \mathrm{O}$ as HTM showed the stability against mechanical damages and protected the absorber layer for 1 month. ${ }^{[26]}$ PSCs with CuSCN as HTM lost $40 \%$ of its initial PCE when average relative humidity is $40 \%$ under annealing temperature of $125^{\circ} \mathrm{C}$ for 2 hours ${ }^{[27]}$ and lost only $5 \%$ of initial PCE under full irradiance at $60{ }^{\circ} \mathrm{C}$ for 42 days $^{[28]}$ exhibiting that device has good thermal and mechanical stability. Furthermore, manufacturing cost is very important for the commercialization of PSCs and high cost of organic HTMs is the main hurdle for this purpose of commercialization. Therefore, search for efficient and cost 
effective HTM is the challenge in order to enhance life time of PSCs and reduce the fabrication cost simultaneously. Thus, it is necessary that cost effective and stable HTM should be used in replacement of expensive and unstable HTMs.

Table 1. Comparison of cost and performance of commonly used HTMs in PSCs

\begin{tabular}{llllllll}
\hline \multicolumn{1}{c}{ Absorber material } & \multicolumn{1}{c}{ HTM } & $\begin{array}{c}\text { Cost } / \mathrm{g} \\
(\$)\end{array}$ & $\begin{array}{c}\text { Device } \\
\text { Architecture }\end{array}$ & Dopants & $\begin{array}{c}\text { PCE } \\
(\%)\end{array}$ & $\begin{array}{l}\mathrm{V}_{\text {oc }} \\
(\mathrm{V})\end{array}$ & Ref \\
\hline $\mathrm{CH}_{3} \mathrm{NH}_{3} \mathrm{PbI}_{3}$ & PEDOT: PSS & $0.9-9.87^{*}$ & Inverted planar & TBP, Li-TFSI & 18.1 & 1.1 & {$[16]$} \\
$\left(\mathrm{FAPbI}_{3}\right)_{1-\mathrm{x}}\left(\mathrm{MAPbBr}_{3}\right)_{\times}$ & PTAA & $2350^{*}$ & Mesoscopic & TBP, Li-TFSI & 20.2 & 1.06 & {$[23]$} \\
$\mathrm{CH}_{3} \mathrm{NH}_{3} \mathrm{PbI}_{3}$ & Spiro-MeOTAD & $383.70^{*}$ & Mesoscopic & TBP, Li-TFSI & 19.7 & 1.0 & {$[13]$} \\
$\mathrm{CH}_{3} \mathrm{NH}_{3} \mathrm{PbI}_{3}$ & P3HT & $544^{*}$ & Mesoscopic & TBP, Li-TFSI & 15.3 & 1.02 & {$[20]$} \\
$\mathrm{CH}_{3} \mathrm{NH}_{3} \mathrm{PbI}_{3}$ & $\mathrm{CuI}$ & $0.5-7.45^{*}$ & Mesoscopic & - & 17.6 & 1.03 & {$[25]$} \\
$\mathrm{CH}_{3} \mathrm{NH}_{3} \mathrm{PbI}_{3}$ & $\mathrm{Cu}$ & $8.2-11.8^{*}$ & Mesoscopic & - & 13.4 & 1.07 & {$[26]$} \\
$\mathrm{CH}_{3} \mathrm{NH}_{3} \mathrm{PbI}_{3}$ & $\mathrm{NiO}$ & $3.5-9.8^{*}$ & Mesoscopic & - & 16.4 & 1.07 & {$[29]$} \\
$\mathrm{CH}_{3} \mathrm{NH}_{3} \mathrm{PbI}_{3}$ & $\mathrm{CuSCN}$ & $0.8-1.4^{*}$ & Mesoscopic & - & 17.1 & 1.01 & {$[30]$} \\
\hline
\end{tabular}

* www.sigmaaldrich.com/germany.html is visited on December 2018 to tag the cost of absorber materials.

Copper thiocyanate, inorganic p-type semi-conductor, is considered to be very promising replacement of organic HTMs. ${ }^{[31]}$ Comparison of cost and performance between CuSCN and various HTMs is shown in Table 1. It is obvious that CuSCN is cost effective and stable HTM for efficient PSCs as evident in Table 1. CuSCN exists in two forms as $\alpha-\mathrm{CuSCN}$ and $\beta-\mathrm{CuSCN}$, while $\beta-\mathrm{CuSCN}$ is readily available and more thermally stable ${ }^{[32]}$ thus is the most suitable candidate for HTM in PSC as well as it has easy solution processability, chemical stability and high optical transparency. ${ }^{[33]}$ Initially, PCE of PSCs with CuSCN as HTM increased up to $12.4 \% .{ }^{[34]}$ Now a days, PCE has been greatly improved and reached up to $17.10 \%$ with pristine absorber and pristine CuSCN film prepared by spray deposition method ${ }^{[30]}$ and up to $18 \%$ with low temperature solution processed $\mathrm{CuSCN}$ as HTM. ${ }^{[27]}$ Although, PCE of PSCs has been improved greatly in recent years by various researchers but still unable to achieve the Shockley-Queisser limit $(31.4 \%)^{[35,36]}$ which is maximum theoretical limit of efficiency. Apart from experimental research, theoretical research is also equally important to optimize device performance and to understand device mechanism properly. Researchers performed the device modelling of lead-based and lead-free PSCs using Solar Cell Capacitance Simulator (SCAPS). ${ }^{\text {[37-41] }}$ 
Very little research work has been done for PSC with CuSCN as HTM. For example, SCAPS was used to simulate the perovskite solar cell with $\mathrm{CuSCN}$ as HTM but only the effect of thickness of absorber layer on the performance of device was studied. ${ }^{[38]}$ In another modelling, PSC was simulated with various HTMs including $\mathrm{CuSCN}$ as HTM and ZnO as ETM but only the effect of thickness, defect density and effective valence band density of absorber were investigated. ${ }^{[42]}$ Besides these physical factors, there are many other factors including shallow doping density in absorber, diffusion length in absorber corresponding to defect density, $\mathrm{VBO}$ and $\mathrm{CBO}$ as well as defects in the interfaces that are critical to define the performance of PSCs. CBO is the difference of CBMs of ETM and absorber at the interface as CBM signifies the lowest vacant electronic states in the material. As proper selection of $\mathrm{CBO}$ and $\mathrm{VBO}$ at ETM/absorber interface and absorber/HTM interface can reduce recombination at interfaces and can enhance charge transport, thus, improving the PCE of the device. Therefore, a detailed and thorough device modelling of PSC is necessary with $\mathrm{TiO}_{2}$ as ETM and CuSCN as HTM with $\mathrm{Pb}$-based absorber with the aim to optimize the device performance and proper understanding of device mechanism. In this paper, a comprehensive investigation is presented about the impact of all above stated physical factors on the performance of PSCs using SCAPS.

\section{Theory and computational details}

The $n-i-p$ architecture of the device includes transparent conducting oxide (TCO) / ETM $\left(\mathrm{TiO}_{2}\right) /$ interface defect layer (IDL1) / absorber $\left(\mathrm{CH}_{3} \mathrm{NH}_{3} \mathrm{PbI}_{3}\right)$ / interface defect layer (IDL2) / HTM (CuSCN) / back metal contact ( $\mathrm{Au}$ ) as shown in Figure 1(a). The band alignment diagram is shown in Figure 1(b). The proper selection of CBO and VBO is very crucial for the transport of photo-excited electrons and holes towards front electrode and back metal contact respectively in order to reduce recombination in the absorber layer. The defect type in the absorber layer is selected as Gaussian distribution defect, capture cross section for holes and electrons is set to be $2 \times 10^{-14} \mathrm{~cm}^{2}$ and characteristic energy is $0.1 \mathrm{eV}$. The defect density is set to be $1 \times 10^{17} \mathrm{~cm}^{-3}$ and defect type is selected as single in the interface defect layers IDL1 and IDL2 dealing with the interface carrier recombination rate at ETM/absorber and 
absorber/HTM interface respectively.
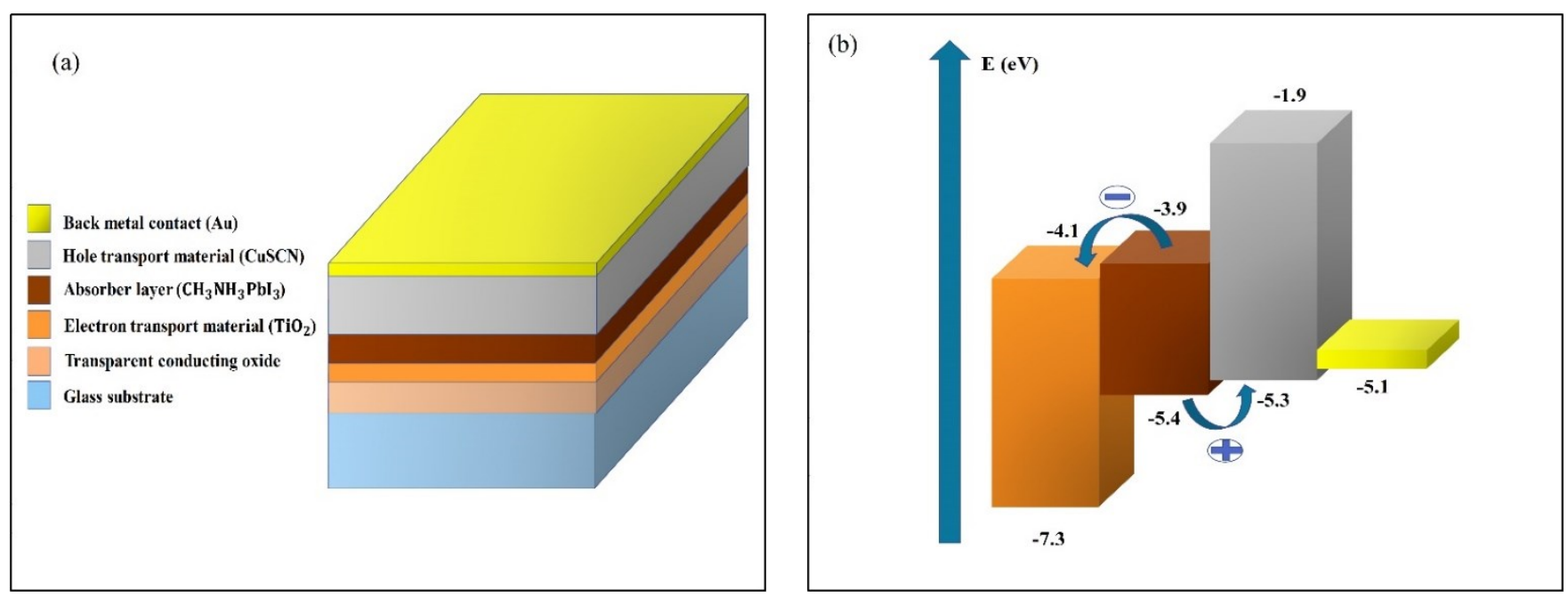

Figure 1. a) Schematic representation of the device structure b) Band diagram of the $\mathrm{TiO}_{2} / \mathrm{CH}_{3} \mathrm{NH}_{3} \mathrm{PbI}_{3} / \mathrm{CuSCN}$ $/ \mathrm{Au}$

. Position of IDL2 is shown in Figure 2(a,b) while position of IDL1 is shown in Figure 3(a, b) for different band offsets. The band offset can be changed by varying the electron affinity of HTM and ETM. The conduction band minimum (CBM) and valence band maximum (VBM) of ETM and HTM is very important to define the barrier for photo generated electrons and holes in absorber respectively. Firstly, if electron affinity of the ETM is larger than the electron affinity of absorber then CBM of ETM is lower than CBM of absorber and energy cliff is formed at ETM/absorber interface thus offering no energy barrier to electrons.
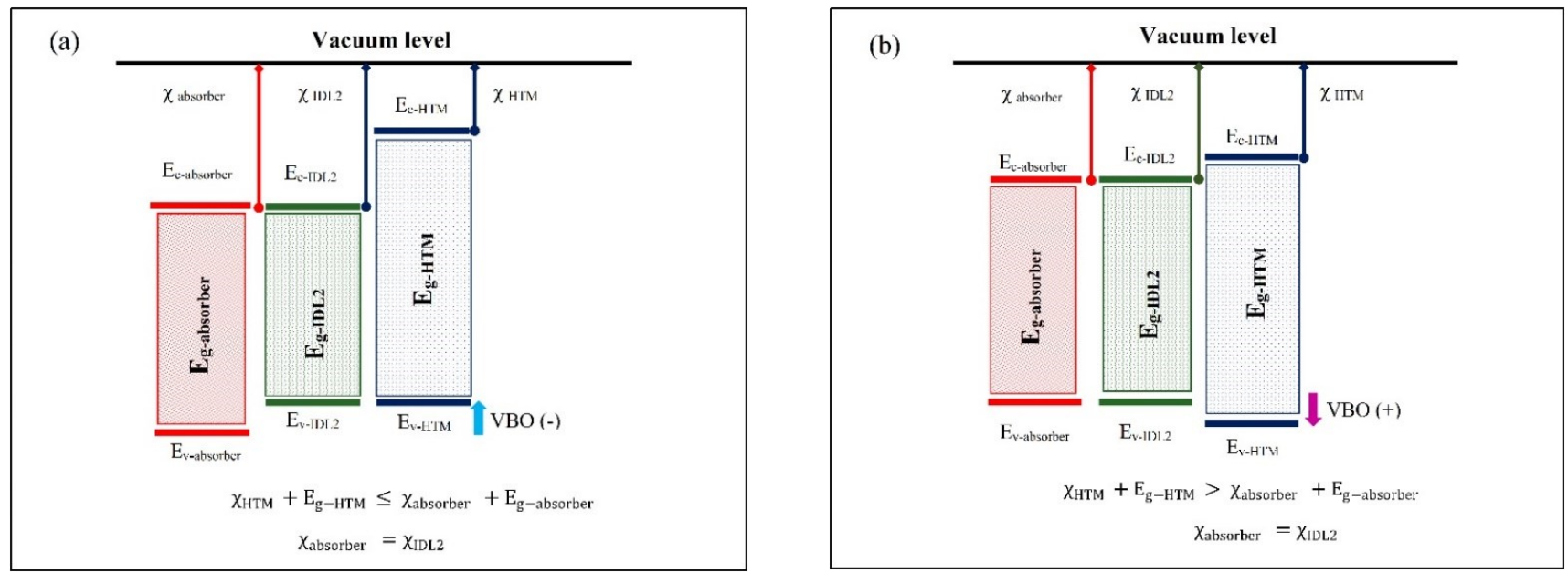

Figure 2. Band alignments of absorber/IDL2/HTM layers with a) negative and b) positive VBO. IDL2 is used to count the recombination at the interface. 

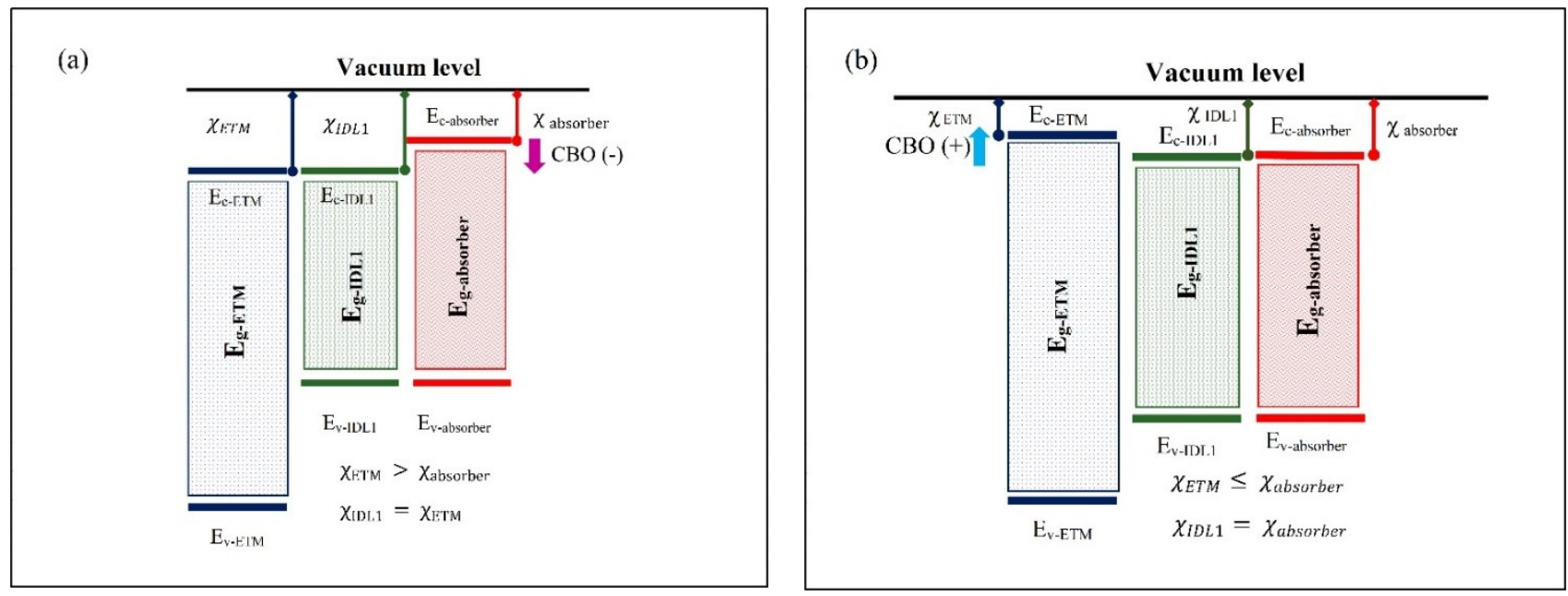

Figure 3. Band alignments of ETM/IDL1/absorber layers with a) negative and b) positive CBO. IDL1 is used to count the recombination at the interface.

Table 2. Simulation parameters of PSC device

\begin{tabular}{|c|c|c|c|c|c|c|}
\hline Parameters & TCO & $\begin{array}{c}\text { ETM } \\
\left(\mathrm{TiO}_{2}\right)\end{array}$ & IDL1 & $\begin{array}{c}\text { Absorber } \\
\left(\mathrm{CH}_{3} \mathrm{NH}_{3} \mathrm{PbI}_{3}\right)\end{array}$ & IDL2 & $\begin{array}{c}\text { HTM } \\
(\mathrm{CuSCN})\end{array}$ \\
\hline Thickness $(\mu \mathrm{m})$ & 0.500 & 0.050 & 0.010 & 0.350 & 0.010 & 0.350 \\
\hline Band gap energy $E_{g}(e V)$ & 3.5 & $3.2^{[43]}$ & 1.50 & $1.50^{[44]}$ & 1.50 & $3.40^{[45]}$ \\
\hline Electron affinity $\chi(\mathrm{eV})$ & 4.0 & $3.9-4.8^{[46-48]}$ & 3.9 & $3.9^{[49]}$ & 3.9 & $1.9^{[50]}$ \\
\hline Relative permittivity $\varepsilon_{\mathrm{r}}$ & 9 & $38-108^{[51]}$ & 6.5 & $6.5^{[52]}$ & 6.5 & $10^{[53]}$ \\
\hline $\begin{array}{l}\text { Effective conduction band } \\
\text { density } \mathrm{N}_{\mathrm{c}}\left(\mathrm{cm}^{-3}\right)\end{array}$ & $2.2 \times 10^{18}$ & $2.2 \times 10^{18[54]}$ & $2.2 \times 10^{18}$ & $2.2 \times 10^{18[55]}$ & $2.2 \times 10^{18}$ & $\underset{[56]}{2.2 \times 10^{19}}$ \\
\hline $\begin{array}{l}\text { Effective valance band } \\
\text { density } \mathrm{N}_{\mathrm{v}}\left(\mathrm{cm}^{-3}\right)\end{array}$ & $1.8 \times 10^{19}$ & $1.8 \times 10^{19}$ & $1.8 \times 10^{19}$ & $1.8 \times 10^{19[55]}$ & $1.8 \times 10^{19}$ & $1.8 \times 10^{18}$ \\
\hline $\begin{array}{l}\text { Electron mobility } \mu_{\mathrm{n}} \\
\left(\mathrm{cm}^{2} \mathrm{~V}^{-1} \mathrm{~s}^{-1}\right)\end{array}$ & 20 & $20^{[57]}$ & 2 & $10^{[58]}$ & 2 & $1 \times 10^{-4}$ \\
\hline $\begin{array}{l}\text { Hole mobility } \mu_{\mathrm{p}} \\
\left(\mathrm{cm}^{2} \mathrm{~V}^{-1} \mathrm{~s}^{-1}\right)\end{array}$ & 10 & $10^{[57]}$ & 2 & 10 & 2 & $\begin{array}{c}1 \times 10^{-2} \\
{[59]}\end{array}$ \\
\hline $\begin{array}{l}\text { Donor concentration } \mathrm{N}_{\mathrm{D}} \\
\left(\mathrm{cm}^{-3}\right)\end{array}$ & $2 \times 10^{19}$ & $1 \times 10^{16}$ & 0 & 0 & 0 & 0 \\
\hline $\begin{array}{l}\text { Acceptor concentration } \mathrm{N}_{\mathrm{A}} \\
\left(\mathrm{cm}^{-3}\right)\end{array}$ & 0 & 0 & $2.2 \times 10^{16}$ & $2.2 \times 10^{16[60]}$ & $2.2 \times 10^{16}$ & $1 \times 10^{16}$ \\
\hline Defect density $\mathrm{N}_{\mathrm{t}}\left(\mathrm{cm}^{-3}\right)$ & $1 \times 10^{15}$ & $1 \times 10^{17}$ & $3 \times 10^{17}$ & $1 \times 10^{17}$ & $3 \times 10^{17}$ & $1 \times 10^{17}$ \\
\hline
\end{tabular}


Secondly, if electron affinity of the ETM is smaller than the electron affinity of absorber then CBM of ETM is higher than CBM of absorber, and energy spike is formed at ETM/absorber interface thus offering energy barrier to electrons. In this way, negative and positive $\mathrm{CBO}$ can be defined for first and second condition respectively. If electron affinity of the HTM is smaller than the electron affinity of the absorber and VBM of HTM is higher than VBM of absorber, then energy cliff is formed at absorber/HTM interface, thus offering no energy barrier to holes. If electron affinity of the HTM is higher than the electron affinity of absorber and VBM of HTM is lower than VBM of absorber, thus energy spike is formed at absorber/HTM interface offering energy barrier to holes. In this way, negative and positive VBO can be defined. The absorption constant in the absorber layer is set as $10^{+5} \mathrm{~cm}^{-1}$. Table 2 summarizes the basic physical parameters for each material and interfaces in the modelling of the device. For simplicity, thermal velocities of holes and electrons are selected as $10^{+7} \mathrm{~cm} / \mathrm{s}$ and optical reflectance at each interface is assumed to be zero. Control variable method is used for the optimization of parameters in the modelling of the device. Device modelling is performed under the standard conditions of irradiance of $1000 \mathrm{~W} / \mathrm{m}^{2}$, temperature of $298 \mathrm{~K}$ and an air mass of $1.5 \mathrm{G}$. SCAPS is based on the differential equations for numerical modelling of solar cells as follows.

$$
\begin{gathered}
-\frac{d}{d x}\left(\frac{d \varphi}{d x}\right)=\frac{d E}{d x}=\frac{e}{\varepsilon \varepsilon_{o}}\left(p-n+N_{n}^{+}-N_{p}^{-}-n_{\text {trap }}+p_{\text {trap }}\right) \\
\frac{1}{e}\left(\frac{d j_{n}}{d x}\right)=P(E) G-\left(1-P(E) \alpha\left(n p-n_{i}^{2}\right)\right. \\
\frac{1}{e}\left(\frac{d j_{p}}{d x}\right)=P(E) G-\left(1-P(E) \alpha\left(n p-n_{i}^{2}\right)\right. \\
j_{n}=e n \mu_{n} E+\mu_{n} k_{B} T \frac{d n}{d x} \\
j_{p}=e p \mu_{p} E-\mu_{p} k_{B} T \frac{d p}{d x}
\end{gathered}
$$

Equation (1) represents the electric field and electric potential which depends on the space charge and doping. Equations (2-5) are current continuity equation represent the charge generation and recombination processes of electrons and holes. $\mathrm{G}$ and $\mathrm{P}(\mathrm{E})$ are the bound exciton generation rate and probability of dissociation of bound exciton respectively while $\mathrm{n}_{\mathrm{i}}$ is the intrinsic carrier concentration. 
Recombination rate $\alpha$ is given by

$$
\alpha=\frac{\mathrm{e}}{\varepsilon \varepsilon_{\mathrm{o}}}\left(\mu_{\mathrm{n}}+\mu_{\mathrm{p}}\right)
$$

$\mu_{\mathrm{n}}$ and $\mu_{\mathrm{p}}$ are the electron and hole mobility respectively, while $\mathrm{j}_{\mathrm{n}}$ and $\mathrm{j}_{\mathrm{p}}$ are electron and hole current densities respectively. It is assumed that diffusion obeys the Einstein relation and diffusivity is proportional to $\mathrm{k}_{\mathrm{B}} \mathrm{T}, \mathrm{k}_{\mathrm{B}}=$ Boltzmann constant $=1.38 \times 10^{23} \mathrm{~J} / \mathrm{K}$. The total current density is given by

$$
\mathrm{J}=\mathrm{j}_{\mathrm{n}}+\mathrm{j}_{\mathrm{p}}
$$

The simulated J-V curve and QE curve with device parameters in Table 2 has been drawn and shown in curve (a) of Figure 4(a, b). The performance parameters such as open-circuit voltage $\left(\mathrm{V}_{\mathrm{oc}}\right)$ of $0.79 \mathrm{~V}$, PCE of $12.36 \%$, short-circuit current density $\left(\mathrm{J}_{\mathrm{sc}}\right)$ of $22.57 \mathrm{~mA} / \mathrm{cm}^{2}$ and fill factor $(\mathrm{FF})$ of $69.72 \%$ are obtained. The performance of simulated device is compared with experimental results of lead-based PSCs with CuSCN as HTM and $\mathrm{TiO}_{2}$ as ETM and it is found that simulated results are consistent with experimental results. ${ }^{[34,61,62]}$ Input parameters in Table 2 are valid due to consistency between results and close to the real devices. The band gap of $\mathrm{CH}_{3} \mathrm{NH}_{3} \mathrm{PbI}_{3}$ corresponds to red shifted optical absorption edge at $830 \mathrm{~nm}$ and maximum absorbance is at $400 \mathrm{~nm}$. The quantum efficiency (QE) covers the whole visible spectrum as shown in curve (a) of Figure 4(b) and is in agreement with the previously reported experimental work. ${ }^{[27,30,34]}$ These parameters were further optimized and discussed in detail in the following section. 

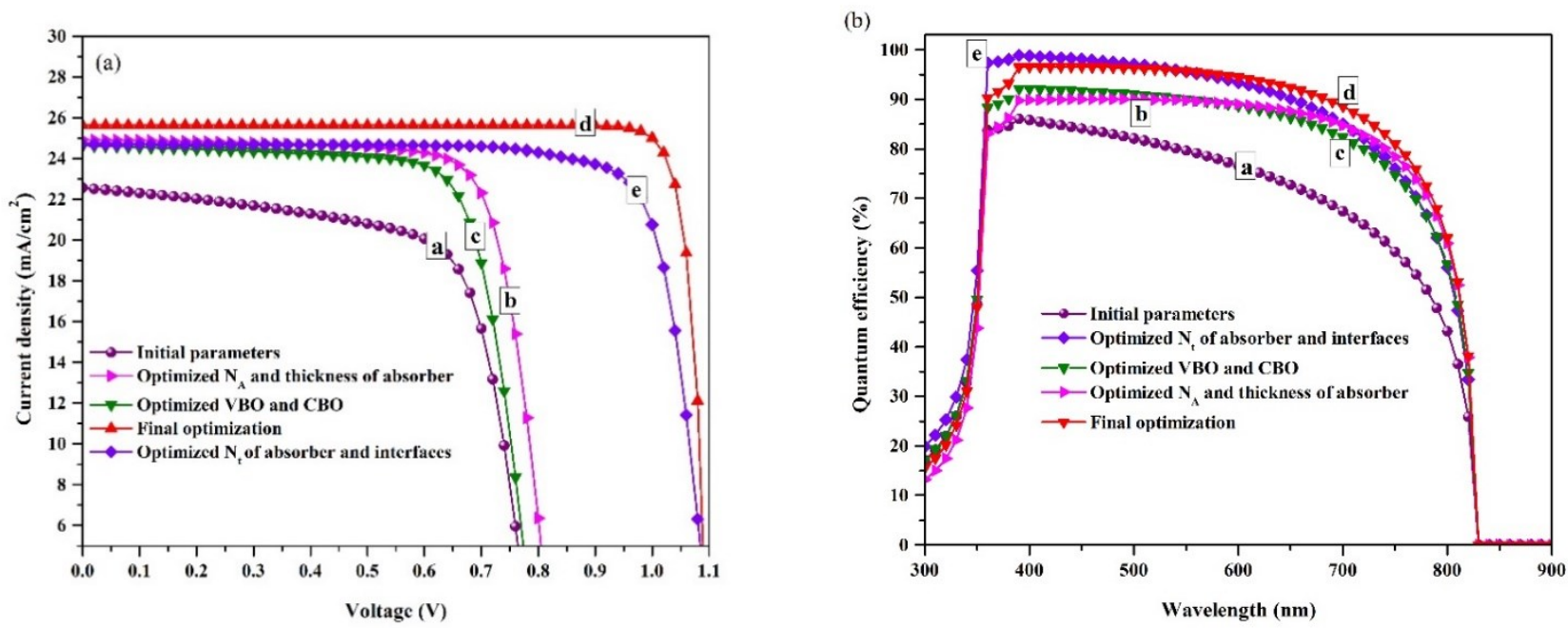

Figure 4. a) J-V curves and b) Quantum efficiency curves of PSC with parameters in Table 2 after device optimization

\section{Results and discussion}

\subsection{Influence of shallow doping density $\left(\mathrm{N}_{\mathrm{A}}\right)$ and thickness of absorber layer}

Doping of absorber is a very critical factor for the performance of PSCs. Doping can be deep level or shallow level. Dopants which are close to the band edges are shallow dopants while away from the band edges are deep dopants. Absorber can be either n-doped or p-doped like other semiconductors. For shallow level doping, usually unintentional self-doping is used in the absorber layer. ${ }^{[63]}$ Thermal annealing or precursor ratio in the solution is used for self-doping in the lead $(\mathrm{Pb})$ based absorber which is very critical to control the charge transport, carrier density and majority carrier type. ${ }^{[64]}$ Methyl ammonium iodide (MAI) and lead iodide $\left(\mathrm{PbI}_{2}\right)$ are involved in the synthesis of $\mathrm{CH}_{3} \mathrm{NH}_{3} \mathrm{PbI}_{3}$ and selfdoping of absorber depends on the ratio of two precursors $\left(\mathrm{PbI}_{2} / \mathrm{MAI}\right)$. Larger ratio of $\left(\mathrm{PbI}_{2} / \mathrm{MAI}\right)$ leads towards n-doped absorber while smaller ratio of ( $\left.\mathrm{PbI}_{2} / \mathrm{MAI}\right)$ leads towards $\mathrm{p}$-doped absorber layer. ${ }^{[65]}$ The influence of shallow doping density on the performance parameters of PSC is studied by selecting the $\mathrm{N}_{\mathrm{A}}$ in the range of $10^{14} \mathrm{~cm}^{-3}$ to $10^{17} \mathrm{~cm}^{-3}$. Figure 5(a) shows the variation in performance parameters with various values of $\mathrm{N}_{\mathrm{A}}$. It is noted that PCE is maximum at $\mathrm{N}_{\mathrm{A}}$ of $2 \times 10^{15} \mathrm{~cm}^{-3}$. QE also increases when value of $\mathrm{N}_{\mathrm{A}}$ ranging from $10^{14} \mathrm{~cm}^{-3}$ to $10^{16} \mathrm{~cm}^{-3}$ and is maximum at $\mathrm{N}_{\mathrm{A}}$ of $2 \times 10^{15} \mathrm{~cm}^{-3}$ as 
shown in Figure 5(b). According to above results, charge carrier transport and collection enhanced at the $\mathrm{N}_{\mathrm{A}}$ of $2 \times 10^{15} \mathrm{~cm}^{-3}$ with the same irradiance. Therefore, performance of the PSCs depends critically on the proper choice of $\mathrm{N}_{\mathrm{A}}$, as, built-in electric field increases with the increase of $\mathrm{N}_{\mathrm{A}}$ leading towards better performance of PSCs because charge carriers are separated more efficiently due to high electric field. ${ }^{[66]}$ In the absence of doping, there is equilibrium state and only one fermi level $\left(\mathrm{E}_{\mathrm{F}}\right)$ exist between electrons and holes within absorber.
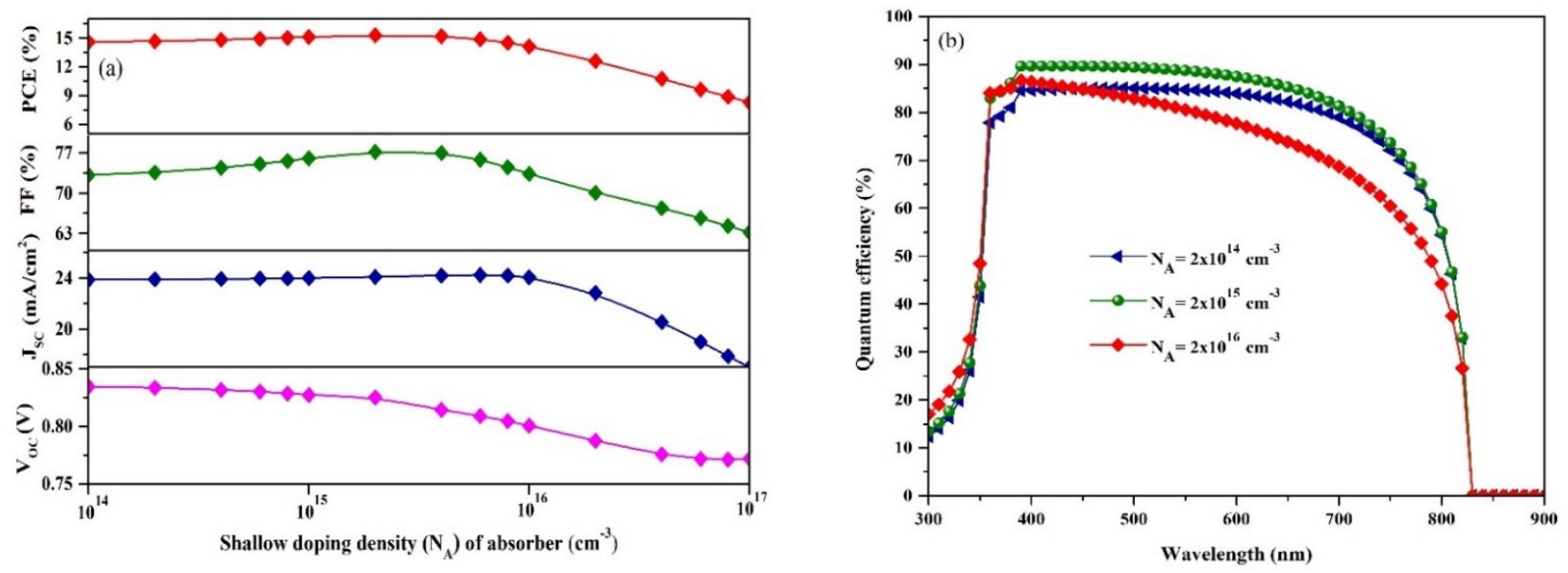

Figure 5. Effect of $\mathrm{N}_{\mathrm{A}}$ of absorber layer on a) performance parameters b) quantum efficiency of PSC

With the doping, equilibrium is disturbed and $\mathrm{E}_{\mathrm{F}}$ splits into two fermi levels known as quasi fermi levels for holes $\left(E_{F}^{p}\right)$ and electrons $\left(E_{F}^{n}\right)$ in the absorber as shown in Figure 6(a). Quasi fermi level is the function of position. In this way absorber's $E_{F}^{p}$ aligns with the HTM's $E_{F}^{p}$, in the meantime, the absorber's $E_{F}^{n}$ aligns with the ETM's $E_{F}^{n}$. This splitting enhances the $\mathrm{V}_{\text {oc }}$ at the open circuit conditions thus enhancing the PCE of the device. ${ }^{[67]}$ If $\mathrm{N}_{\mathrm{A}}$ increases then quasi fermi level $E_{F}^{p}$ shifts away from VBM of absorber and eventually flattens into the $E_{F}^{p}$ of HTM as shown in Figure 6(b). Hole transportation and extraction is strongly affected by this alignment and hole density is decreased as indicated from the uplift of $E_{F}^{p}$ of absorber leading towards reduced performance. Absorber thickness is another physical parameter which affects the performance of PSC. In a thin absorber layer, the charge carrier diffusion length is larger than the thick one because majority of charge carriers are capable to 
reach the electrodes to produce electrical power, while too thin absorber layer is not beneficial for the complete absorption of sun light leading towards decrease in performance. Light absorption increases with the increase in thickness of absorber and more charge carriers are generated resulting in the increase of $\mathrm{J}_{\mathrm{sc}}$ and photovoltaic performance increases gradually. When the absorber is too thick then charge carriers have to travel long path to reach respective electrode and chance of recombination increases.
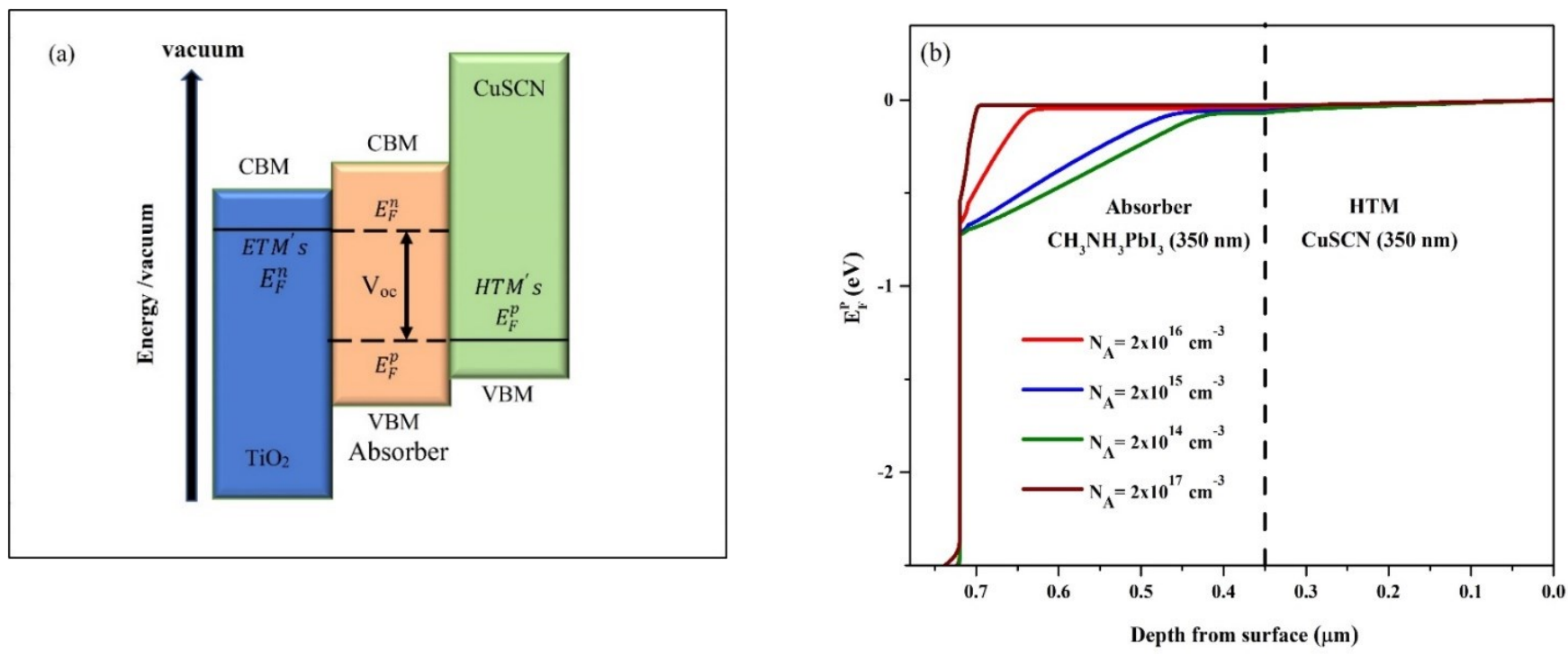

Figure 6. a) The quasi-Fermi level splitting in the absorber layer with pristine $\mathrm{TiO}_{2}$ and pristine $\mathrm{CuSCN}$ at open circuit condition $\mathrm{b}$ ) Distribution of quasi fermi level of hole for different values of $\mathrm{N}_{\mathrm{A}}$ of absorber

Variation in performance parameters and QE of PSCs with increase in absorber thickness is shown in Figure $7(a, b)$ respectively. Initially, The PCE increases gradually with the increase in thickness of the absorber but progress in PCE slows down and becomes almost constant with the thickness. The QE increases with the increase in thickness of absorber layer but QE curves begin to overlap at $420 \mathrm{~nm}$ thickness of absorber. The optimized thickness of absorber is chosen as $420 \mathrm{~nm}$. Upon optimizing the absorber's thickness $(420 \mathrm{~nm})$ and $\mathrm{N}_{\mathrm{A}}\left(2 \times 10^{15} \mathrm{~cm}^{-3}\right)$, the improved performance parameters of PSC with PCE of $15.77 \%, \mathrm{~J}_{\mathrm{sc}}$ of $24.93 \mathrm{~mA} / \mathrm{cm}^{2}, \mathrm{~V}_{\mathrm{oc}}$ of $0.82 \mathrm{~V}$ and $\mathrm{FF}$ of $76.88 \%$ are shown in curve (b) of Figure $4(a, b)$. This significant device performance is due to the lower recombination rate and large diffusion length. The device performance can further be improved for the complete solar spectrum absorption if 
collection of charge carrier is excellent in the increasing thickness of absorber layer.
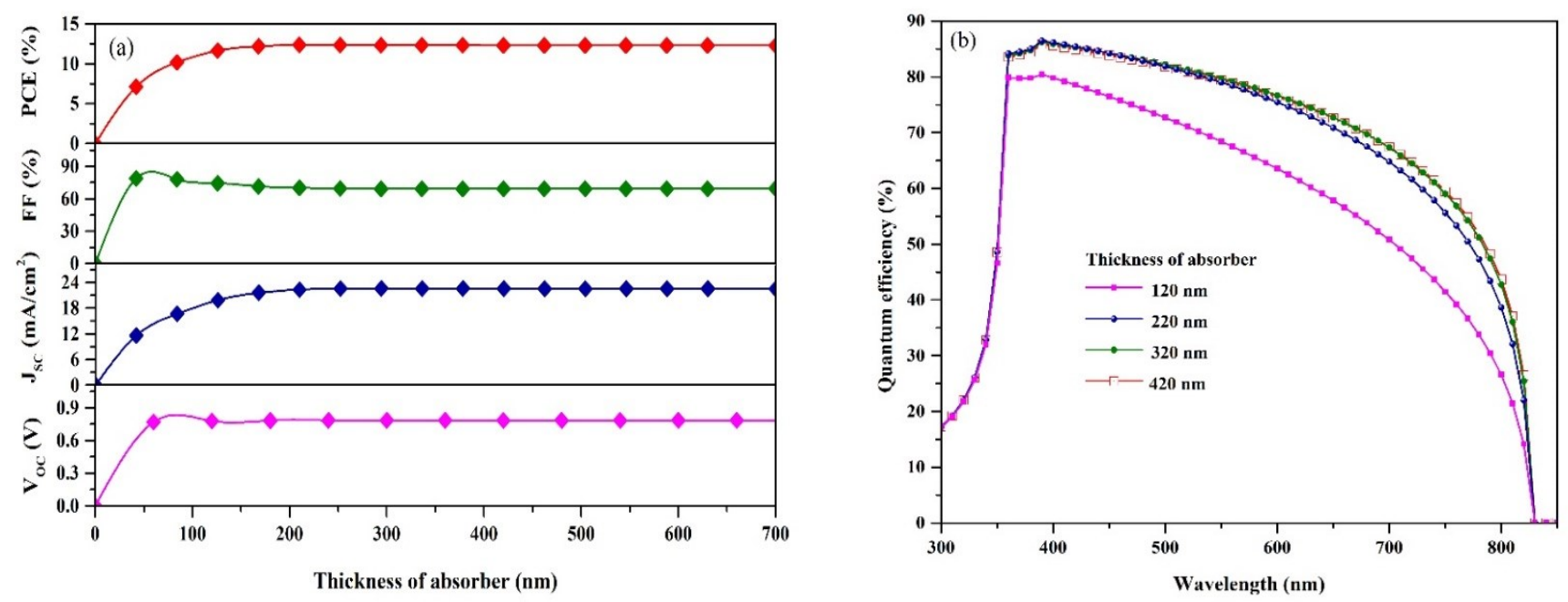

Figure 7. Effect of thickness of absorber layer on a) performance parameters and b) quantum efficiency of PSC

\subsection{Influence of defect density $\left(\mathrm{N}_{\mathrm{t}}\right)$ of interfaces and absorber}

The performance of PSCs can be optimized by selecting suitable $\mathrm{N}_{t}$ in the absorber layer and strongly effected by morphology and quality of absorber layer. ${ }^{[68]}$ Low quality absorber layer cannot have the proper coverage of lead perovskite on $\mathrm{TiO}_{2}$ layer. ${ }^{[69,70]}$ High defect density in the absorber layer results in poor quality of film leading towards the high recombination rate. Diffusion length is the product of life-time and mobility of charge carrier and quality of the absorber layer is, mostly, represented by diffusion length of charge carriers. This is due to fact that collection of charge carriers is made possible by electric field. Figure 8 shows the effect of $\mathrm{N}_{\mathrm{t}}$ of absorber and corresponding diffusion length of charge carriers on the performance of PSCs. Table 3 shows the various value of $\mathrm{N}_{t}$ varying from $1 \times 10^{14}$ to $1 \times 10^{20} \mathrm{~cm}^{-3}$ and corresponding diffusion lengths from $113.4 \mu \mathrm{m}$ to $0.11 \mu \mathrm{m}$. It was observed to be strongly affected by $\mathrm{N}_{t}$ which is an important parameter affecting the efficiency of PSCs. FF was as low as $\sim 52 \%$ at $\mathrm{N}_{\mathrm{t}}$ of $1 \times 10^{20} \mathrm{~cm}^{-3}$ and saturated to $\sim 75 \%$ for $\mathrm{N}_{\mathrm{t}}$ smaller than $1 \times 10^{15} \mathrm{~cm}^{-3}$. Saturation value of $\mathrm{J}_{\mathrm{sc}}$ and $\mathrm{V}_{\mathrm{oc}}$ was observed to be $23.95 \mathrm{~mA} / \mathrm{cm}^{2}$ and $0.79 \mathrm{~V}$ respectively for $\mathrm{N}_{\mathrm{t}}$ smaller 
than $1 \times 10^{15} \mathrm{~cm}^{-3}$. Performance parameters of PSCs especially FF are most sensitive to $\mathrm{N}_{\mathrm{t}}$. This is due to the fact that when forward biased

is increased then applied electric field to the absorber is decreased. Thus, reduction in electric field leads towards the weak collection of photo generated charge carriers. On the contrary, electric field always assists the collection of charge carriers at short circuit conditions. Absorber should have high quality to achieve the high FF but high $\mathrm{V}_{\mathrm{oc}}$ and $\mathrm{J}_{\mathrm{sc}}$ can be quite simply obtained. As $\mathrm{N}_{\mathrm{t}}$ of $1 \times 10^{14} \mathrm{~cm}^{-3}$ cannot be realized in experimental work easily, therefore, we optimized the $N_{t}$ as $1 \times 10^{15} \mathrm{~cm}^{-3}$ because performance shows almost the same behaviour as that of $1 \times 10^{14} \mathrm{~cm}^{-3}$.

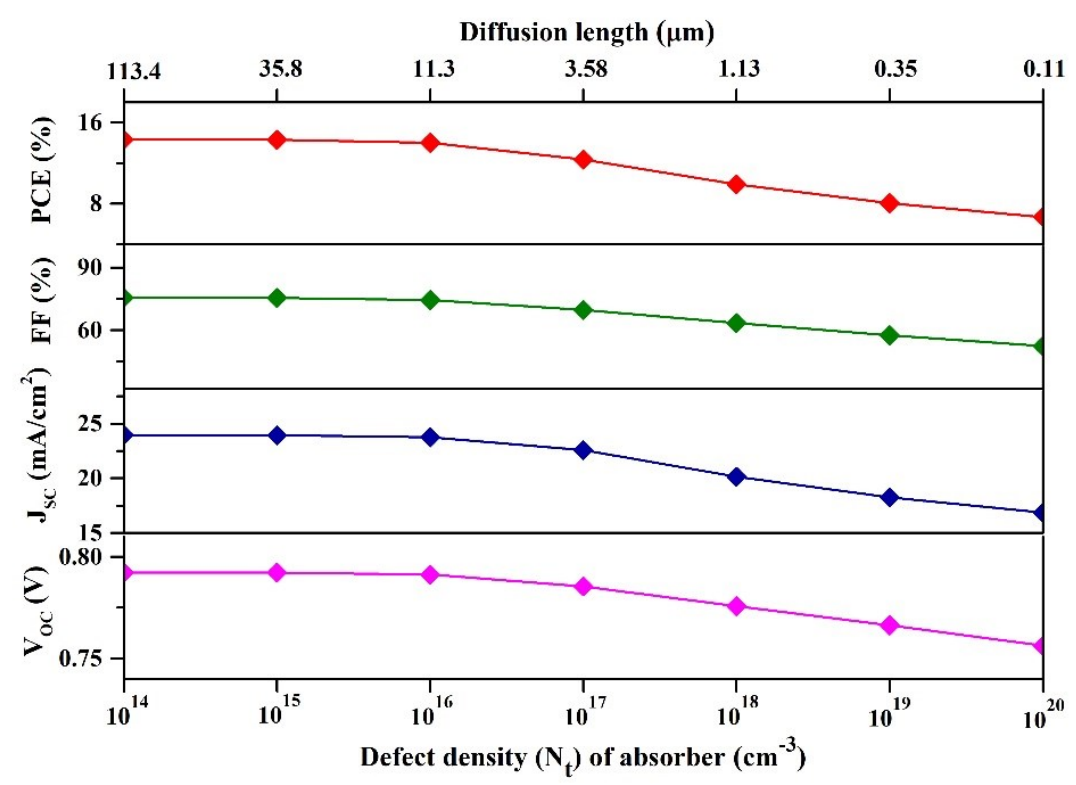

Figure 8. Effect of diffusion lengths and $\mathrm{N}_{\mathrm{t}}$ of absorber layer on performance parameters of PSC

$\tau_{n, p}$ is the charge carrier life time

$$
\tau_{\mathrm{n}, \mathrm{p}}=\frac{1}{\sigma_{\mathrm{n}, \mathrm{p}} \cdot \mathrm{v}_{\mathrm{th}} \cdot \mathrm{N}_{\mathrm{t}}}
$$

$\sigma_{\mathrm{n}, \mathrm{p}}$ represents the electron and hole capture cross-section, trap defect density is represented by $\mathrm{N}_{\mathrm{t}}$ and $\mathrm{V}_{\mathrm{th}}$ is the thermal velocity equals $10^{+7} \mathrm{~cm} / \mathrm{s}$. Diffusion coefficient is represented by $\mathrm{D}$

$$
\mathrm{D}=\frac{\mu \mathrm{k}_{\mathrm{B}} \mathrm{T}}{\mathrm{q}}
$$


$\mathrm{k}_{\mathrm{B}}$ and $\mu$ represent Boltzmann constant and carrier mobility while $q$ and $\mathrm{T}$ represent magnitude of charge and temperature in kelvin. Diffusion length is represented by $\mathrm{L}$

$$
\mathrm{L}=\sqrt{\mathrm{D} \tau}
$$

Diffusion length can be calculated for electrons and holes by using equations (8-10). In this device modelling, physical parameters in the absorber layer is chosen to be same including mobility, hole and electron capture cross section as well as thermal velocity. Therefore, holes and electrons have same simulated values of diffusion lengths. But effective mass of the hole is slightly larger than electron thus having small diffusion length. The performance of PSCs and planar heterojunction solar cells is enhanced for larger diffusion lengths. ${ }^{[71,72]}$ This difference in diffusion lengths have very little influence on the results of simulation and thus can be ignored.

Table 3. Different $\mathrm{N}_{\mathrm{t}}$ values of absorber layer and corresponding diffusion lengths

\begin{tabular}{c|lllllll}
\hline $\mathrm{N}_{\mathrm{t}}\left(\mathrm{cm}^{-3}\right)$ & $1 \times 10^{14}$ & $1 \times 10^{15}$ & $1 \times 10^{16}$ & $1 \times 10^{17}$ & $1 \times 10^{18}$ & $1 \times 10^{19}$ & $1 \times 10^{20}$ \\
\hline Diffusion length $(\mu \mathrm{m})$ & 113.4 & 35.8 & 11.3 & 3.58 & 1.13 & 0.35 & 0.11 \\
\hline
\end{tabular}

Recombination rate and interface defects are the important parameters for the quality of interface, which in turn is the key parameter to enhance the PCE of PSCs. Therefore, $\mathrm{N}_{t}$ at the interfaces varied significantly to show the trend of interface quality. The value of $\mathrm{N}_{\mathrm{t}}$ is varied from $1 \times 10^{12} \mathrm{~cm}^{-3}$ to $1 \times$ $10^{20} \mathrm{~cm}^{-3}$ for IDL1 and IDL2 with constant thickness of $0.001 \mu \mathrm{m}$. The effect of $\mathrm{N}_{\mathrm{t}}$ on J-V curves for ETM/absorber and absorber/HTM is shown in Figure 9(a, b). Figure 9(c) indicates that $N_{t}$ of the ETM/absorber interface has strong influence on the performance parameters and improvement of the junction quality leading towards the high PCE of over 15\% as in Figure 9(a). On the contrary, Figure 9(b) shows that $\mathrm{N}_{t}$ of absorber/HTM interface has small effect on J-V curves. When the device is illuminated, electron and hole pairs are generated, and these are high in number at front surface and significantly decreases at back surface due to high absorption co-efficient of absorber. 

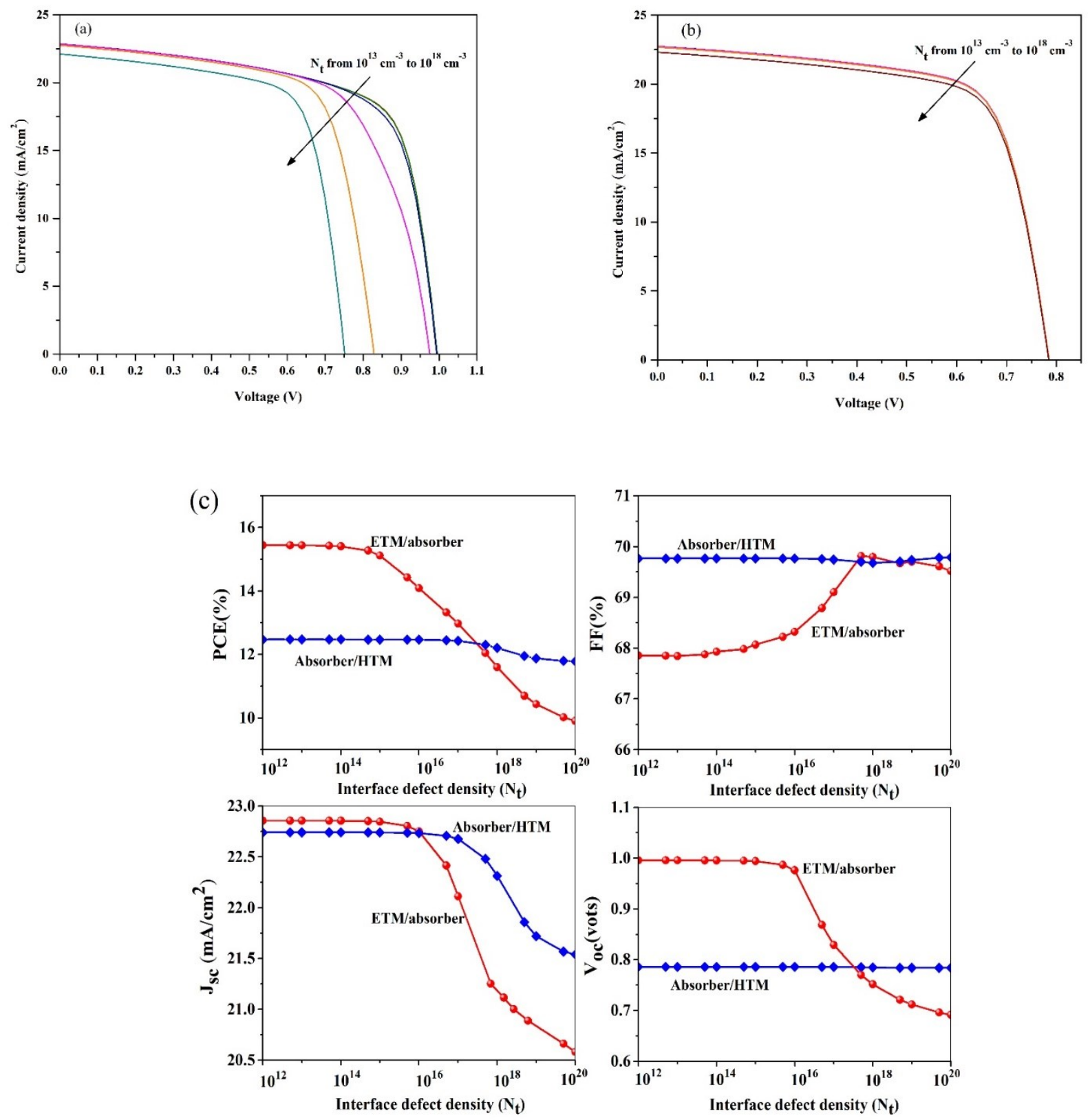

Figure 9. Effect of $\mathrm{Nt}$ on $\mathrm{J}-\mathrm{V}$ curve for a) ETM/absorber interface b) absorber/HTM interface c) Variation in performance parameters with different $\mathrm{N}_{\mathrm{t}}$ at interfaces

As recombination rate directly depends on the generation rate of charge carriers, therefore, more recombination can occur at ETM/absorber interface than absorber/HTM interface. It is concluded that, front side interface is relativity important than back side interface in PSCs and the quality of the interfaces depends on the diffusion lengths of holes and electrons as well as absorption co-efficient. There are interface defects, usually represented by defect density, which affect the transport of photo induced charge carriers across the interface due to lattice mismatch, poor coordination of electrons and 
holes and dislocations at the interfaces. This can be controlled by controlling charge losses and adopting some suitable film deposition methods like atomic layer deposition, chemical vapour deposition, metalorganic chemical vapour deposition and molecular beam epitaxy. ${ }^{[73]} \mathrm{A}$ theoretical guide is very critical to experimental modification of the interfaces in PSCs. ${ }^{[74]}$ Furthermore, charge separation, charge collection and recombination rate are dominant processes that affect the PCE and occur at the interface. In ETM/absorber interface, electron extraction rate can reach up to $10^{9} / \mathrm{s}$ in $\mathrm{TiO}_{2}$ based $\mathrm{PSC}$ as in our proposed device. In order to enhance the charge extraction and interface quality, graphene quantum dots can be introduced into $\mathrm{TiO}_{2} /$ absorber interface which decreases the transport time from 280 ps to 90 ps. ${ }^{[75]}$ There are numerous trap defects in mesoporous $\mathrm{TiO}_{2}$ layer leading towards the slow charge transport at the interface. Fullerene monolayer can be used to modify the ETM/absorber interface in order to transport the electrons quickly across the interface and control their flow in the absorber layer

by interface electronic coupling. ${ }^{[76]}$ Also, Mesoporous $\mathrm{TiO}_{2}$ can be doped with lead $(\mathrm{Pb})$ to synthesize nanofibers by electro spun method in order to separate and transmit electrons by enhancing the quality of interface. ${ }^{[77]}$ Therefore, it is good choice to enhance the quality of interfaces by the reduction of defects in fabricating the more efficient PSCs. Upon optimizing the defect density of ETM / absorber and absorber / HTM interface as well as of absorber itself as $1 \times 10^{15} \mathrm{~cm}^{-3}$, the performance parameters are improved as PCE of $21.94 \%, \mathrm{~J}_{\mathrm{sc}}$ of $24.71 \mathrm{~mA} / \mathrm{cm}^{2}, \mathrm{~V}_{\text {oc }}$ of $1.1 \mathrm{~V}$ and $\mathrm{FF}$ of $80.60 \%$. The simulated $\mathrm{J}-\mathrm{V}$ curve and QE curve with optimized defect density are shown in curve (e) of Figure 4(a, b) respectively.

\subsection{Influence of CBO and VBO}

Band offset is very important factor to deal carrier recombination at the ETM/absorber and absorber/HTM interfaces and is the measure of $\mathrm{V}_{\mathrm{oc}}$. When HTMs make contact with absorber layer then hole extraction and hole transport from absorber layer is strongly dependent on the energy level alignment between absorber/HTM interface ${ }^{[78,79]}$ as illustrated from Figure 10(a-d). 

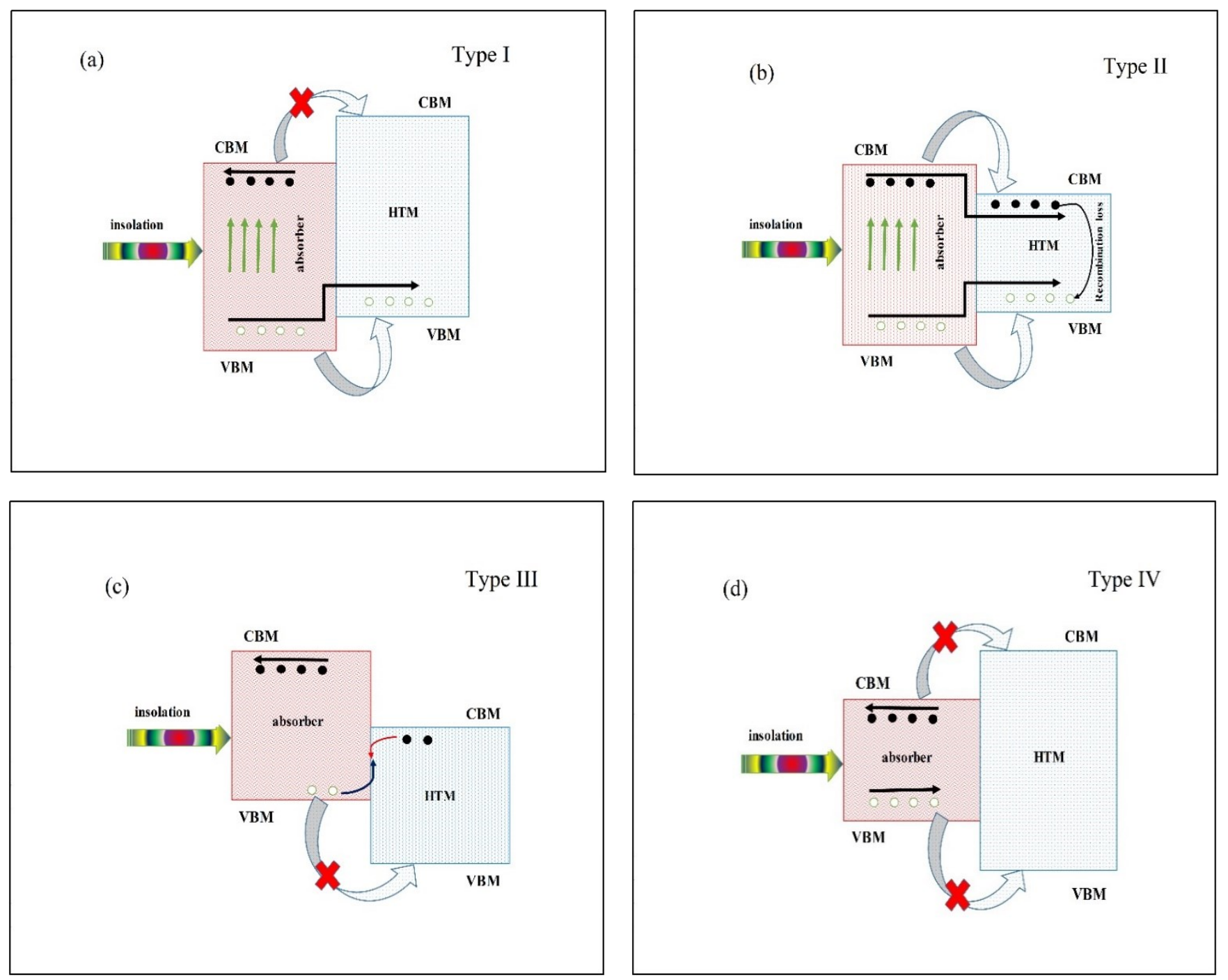

Figure 10. Graphic representation of energy level arrangements at absorber/HTM interface. a) High level and low level VBM of HTM and absorber respectively, Type I staggered band gap b) small band gap of HTM in contact with large band gap of absorber, Type II straddling band gap c) Deep level and high level lying of VBM of HTM and absorber respectively, Type III reverse staggered band gap d) Large band gap of HTM in contact with small band gap of absorber, Type IV reverse straddling band gap.

Type I energy level offset is staggered gap in which CBM and VBM of HTM is higher than CBM and VBM of absorber leading towards the allowed barrier for hole transport and blocking behaviour for electrons transport (Figure 10(a)) and vice versa for ETM. Type II energy level offset is straddling gap shown in Figure 10(b). In the absence of electron blocking layer, recombination loss of electron and hole occur in HTM. In case of deep VBM of HTM, type III or reverse staggered energy level offset exist shown in Figure 10(c), Potential barrier is found for the transport of hole from the VBM of absorber to 
VBM of HTM and this barrier is unavoidable. Therefore, there is recombination between electrons in CBM of HTM and holes in VBM of absorber. It is shown in Figure 10(d), there is deep lying VBM of HTM with wide band gap being un favourable for charge dynamics in absorber as well as in HTM layer known as reverse straddling type IV gap. Therefore, it is most important requirement in pursuit of highly efficient PSCs to match the electronic energy levels with charge transport materials (ETM and HTM) leading towards minimal energy loss and reduced recombination rate of carriers. ${ }^{\left[{ }^{80]}\right.}$ Our proposed device model is type I which is most suitable for efficient charge transport with minimum carrier recombination. But it is still imminent that the energy level should be optimized in order to enhance the performance of the device. By varying the values of $\mathrm{CBO}(-0.3 \mathrm{eV}$ to $+0.3 \mathrm{eV})$ and $\mathrm{VBO}(-0.3 \mathrm{eV}$ to $+0.3 \mathrm{eV})$, optimized values of band offset are estimated at the interfaces. Figure 11(a, b) show variation of PCE, $\mathrm{V}_{\mathrm{oc}}, \mathrm{J}_{\mathrm{sc}}$ and FF with $\mathrm{CBO}$ and $\mathrm{VBO}$ respectively. The band offsets can be changed by adjusting the electron affinity of ETM and HTM. The positive $\mathrm{CBO}$ and negative VBO give the better performance parameters of PSCs. When the VBO is equal to and greater than $+0.1 \mathrm{eV}$ then performance parameters begins to decrease appreciably as shown in Figure 11(a) leading towards reverse straddling gap. Similarly, when $\mathrm{CBO}$ is equal to and less than $-0.1 \mathrm{eV}$ then performance parameters begins to decrease appreciably as shown in Figure 11(b) leading towards degraded performance of the device. PCE of $16.14 \%, \mathrm{~J}_{\mathrm{sc}}$ of $22.99 \mathrm{~mA} / \mathrm{cm}^{2}, \mathrm{~V}_{\mathrm{oc}}$ of $0.96 \mathrm{~V}$ and $\mathrm{FF}$ of $72.88 \%$ are obtained upon optimizing values of VBO $(+0.1 \mathrm{eV})$ and $\mathrm{CBO}(-0.1 \mathrm{eV}) . \mathrm{J}-\mathrm{V}$ curve and QE curve are optimized with improved $\mathrm{CBO}$ and VBO values is shown in curve (c) of Figure $4(\mathrm{a}, \mathrm{b})$ respectively. It is obvious that proper choice of HTM and ETM with improved VBO and $\mathrm{CBO}$ can minimize the recombination rate of electrons and holes thus performance of PSCs can further be optimized. ${ }^{[81]}$ At the end, considering all the optimized parameters listed in Table 4, encouraging results were obtained, i.e., $\mathrm{J}_{\mathrm{sc}}$ of $25.64 \mathrm{~mA} / \mathrm{cm}^{2}, \mathrm{~V}_{\mathrm{oc}}$ of $1.1 \mathrm{~V}, \mathrm{FF}$ of $88.98 \%$ and PCE of $25.02 \%$. The performance parameters corresponding to respective optimized parameter and final optimised J-V curve are shown in Table $\mathbf{5}$ and curve (d) of Figure 4(a) respectively. 

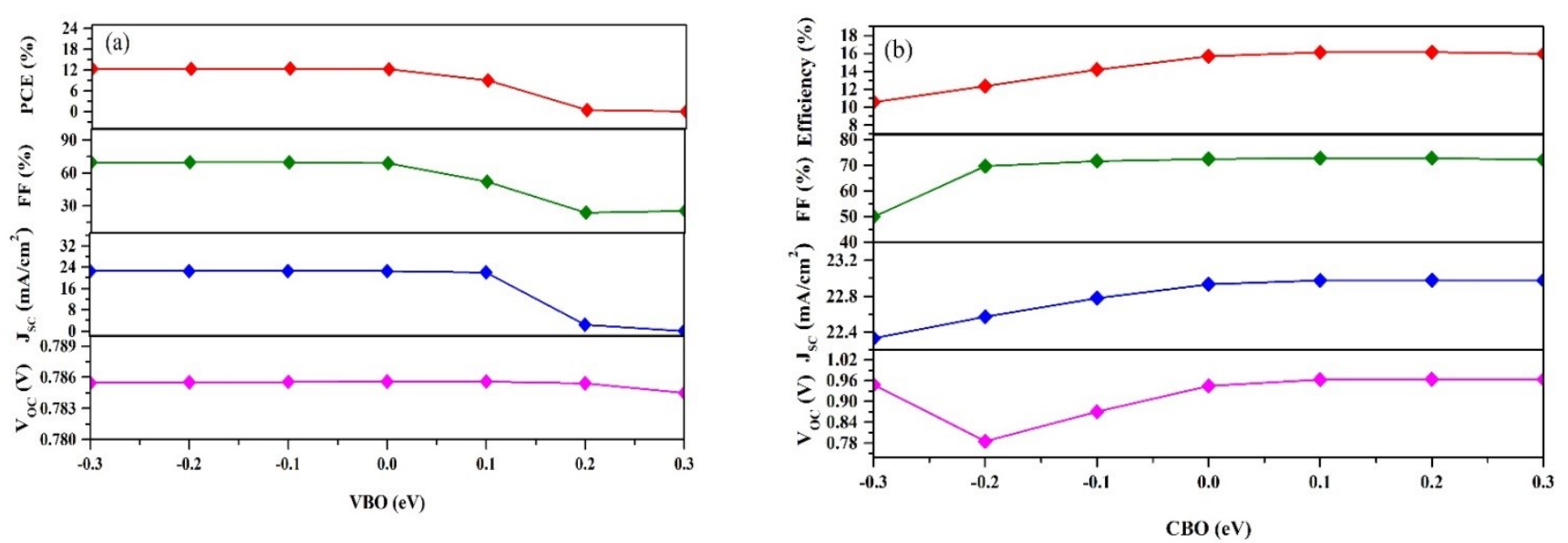

Figure 11. Effect of (a) different VBO at absorber/ HTM interface (b) different CBO at ETM/absorber interface on performance parameters of PSC.

Table 4. Device parameters after optimization

\begin{tabular}{lccc}
\hline Optimized parameters & $\mathrm{TiO}_{2} / \mathrm{CH}_{3} \mathrm{NH}_{3} \mathrm{PbI}_{3}$ & $\mathrm{CH}_{3} \mathrm{NH}_{3} \mathrm{PbI}_{3}$ & $\mathrm{CH}_{3} \mathrm{NH}_{3} \mathrm{PbI}_{3} / \mathrm{CuSCN}$ \\
\hline Shallow Doping density $\left(\mathrm{cm}^{-3}\right)$ & - & $2 \times 10^{15}$ & - \\
Thickness $(\mathrm{nm})$ & - & 420 & - \\
Band offset $(\mathrm{eV})$ & +0.1 & - & -0.1 \\
Defect density $\left(\mathrm{cm}^{-3}\right)$ & $1 \times 10^{15}$ & $1 \times 10^{15}$ & $1 \times 10^{15}$ \\
\hline
\end{tabular}

Our simulated results are compared with the experimental work reported previously and is summarized in Table 5. In the literature, the best efficiency of $18 \%$ has been achieved for PSCs with CuSCN as HTM when absorber is pristine and $20.2 \%$ when absorber is doped and mixed. It is also evident from Table 5 that device modelling of PSC with CuSCN as HTM retrieved better results upon optimization In the previous device modelling of PSC with CuI as HTM showed the PCE of $21.32 \%{ }^{[41]}$ while device modelling of PSC with CuSCN as HTM exhibits the PCE of $25.02 \%$ which is more remarkable. Our simulated value of $\mathrm{V}_{\mathrm{oc}}(1.1 \mathrm{~V})$ is equal to the value reported in the literature as cited in Table 5. In order to achieve the PCE of $21.94 \%$ and $25.02 \%, \mathrm{~J}_{\mathrm{sc}}$ and FF still need to be improved. This improvement in FF and $\mathrm{J}_{\mathrm{sc}}$ might be achieved by better crystalline quality and morphology of absorber and CuSCN layers as well as better interface between $\mathrm{TiO}_{2}$, absorber and CuSCN. Doping of absorber and $\mathrm{CuSCN}$ could further enhance the interface and VBO of absorber / HTM interface. 
Table 5. Performance parameters of PSCs reported in the experimental work in the literature with $\mathrm{CuSCN}$ as HTM and our SCAPS simulated results.

\begin{tabular}{|c|c|c|c|c|c|c|c|c|c|c|c|}
\hline Performance & \multicolumn{5}{|c|}{ Simulation of our proposed cell } & \multicolumn{6}{|c|}{ Experimental work reported in literature } \\
\hline & $: \stackrel{\text { : }}{\stackrel{\Xi}{\Xi}}$ & 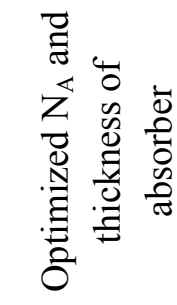 & 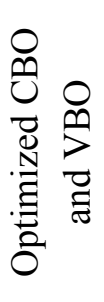 & 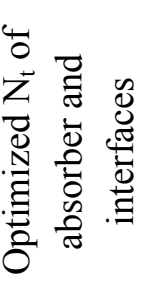 & 폴. & [61] & [34] & [82] & [30] & [27] & [28] \\
\hline PCE $(\%)$ & 12.36 & 15.77 & 16.14 & 21.94 & 25.02 & 11.96 & 12.4 & 16.6 & 17.10 & 18.0 & 20.2 \\
\hline $\mathrm{FF}(\%)$ & 69.72 & 76.88 & 72.88 & 80.60 & 88.98 & 68 & 62 & 69 & 73.09 & 75.3 & 75 \\
\hline $\mathrm{J}_{\mathrm{sc}}\left(\mathrm{mA} / \mathrm{cm}^{2}\right)$ & 22.57 & 24.93 & 22.99 & 24.71 & 25.64 & 18.23 & 19.7 & 21.8 & 23.10 & 23.1 & 22.65 \\
\hline $\mathrm{V}_{\mathrm{oc}}(\mathrm{V})$ & 0.79 & 0.82 & 0.96 & 1.1 & 1.1 & 0.96 & 1.01 & 1.1 & 1.01 & 1.04 & 1.09 \\
\hline
\end{tabular}

\section{Conclusion}

In this work, CuSCN have been used as HTM for the device optimization of Pb based PSC by one dimensional device simulator SCAPS. The results show that PCE of the device has been enhanced when absorber layer is self-doped with suitable shallow doping density as electric field is increased at the interfaces. Fermi level in the absorber layer is splitted into two quasi Fermi levels results in enhanced $\mathrm{V}_{\mathrm{oc}}$ leading towards improved PCE of the device. When doping concentration is too high, recombination rate increases which is the cause of lower PCE. Proper choice for CBO and VBO is made to overcome the recombination rates at ETM /absorber and absorber/HTM interfaces respectively. In the modelling, quality of absorber layer and interfaces is found to be important parameter for the high performance of the device where defect density corresponds to the quality of the absorber layer and interfaces. By selecting the defect density as $1 \times 10^{15} \mathrm{~cm}^{-3}$ in the absorber and ETM/absorber and absorber/HTM interfaces, charge carrier transport and extraction increase leading towards the enhancement of PCE of PSCs from $12.36 \%$ to $21.93 \%$. Light absorption in the absorber layer can be increased with optimized $\mathrm{N}_{\mathrm{A}}$ of $1 \times 10^{15} \mathrm{~cm}^{-3}$ and thickness of $420 \mathrm{~nm}$, thus, PCE of the device enhances up to $15.77 \%$. With all optimized parameters, overall PCE increases up to $25.02 \%$ which is encouraging. According to simulation results, $\mathrm{CuSCN}$ has the potential to be used with $\mathrm{CH}_{3} \mathrm{NH}_{3} \mathrm{PbI}_{3}$ and is good substitute of the 
organic HTMs including, commonly used HTM, spiro-MeOTAD. PCE of the device can further be enhanced by optimizing the fabrication process.

\section{Acknowledgments}

The authors heartiest acknowledgment goes to Dr. Marc Burgelman at the University of Gent for allowing the use of SCAPS-1D.

\section{References}

[1]. R. Fan, Y. Huang, L. Wang, L. Li, G. Zheng, H. Zhou, Adv. Energy Mater. 2016, 6, 1600460.

[2]. W. S. Yang, B.-W. Park, E. H. Jung, N. J. Jeon, Y. C. Kim, D. U. Lee, S. S. Shin, J. Seo, E. K. Kim, J. H. Noh, S. I. Seok, Science. 2017, 356, 1376.

[3]. Y. Xiong, Y. Liu, K. Lan, A. Mei, Y. Sheng, D. Zhao, H. Han, New J. Chem. 2018, 42, 2669.

[4]. P. Zhang, J. Wu, T. Zhang, Y. Wang, D. Liu, H. Chen, L. Ji, C. Liu, W. Ahmad, Z. D. Chen, S. Li, Adv. Mater. 2018, 30, 1703737.

[5]. T. Jiang, W. Fu, RSC Adv. 2018, 8, 5897.

[6]. S. Chen, S. Yang, H. Sun, L. Zhang, J. Peng, Z. Liang, Z. S. Wang, J. Power Sources. 2017, 353, 123.

[7]. A. K. Jena, Y. Numata, M. Ikegami, . Miyasaka, J. Mater. Chem. A. 2018, 6, 2219.

[8]. C. H. Ng, T. S. Ripolles, K. Hamada, S. H. Teo, H. N. Lim, J. Bisquert, S. Hayase, Sci. Rep. 2018, 8, 2482

[9]. M. Neophytou, J. Griffiths, J. Fraser, M. Kirkus, H. Chen, C. B. Nielsen, I. McCulloch, J. Mater. Chem. C. 2017, 5, 4940.

[10]. T. A. Berhe, W. N. Su, C. H. Chen, C. J. Pan, J. H. Cheng, H. M. Chen, M. C. Tsai, L. Y. Chen, A. A. Dubale, B. J. Hwang, Energy Environ. Sci. 2016, 9, 323.

[11]. G. H. Rahmi, P. Pratiwi, B. W. Nuryadi, A. H. Aimon, T. Winata, F. Iskandar, J. Phys. Conf. Ser. 2016, 739, 012050 . 
[12]. N. Cai, S. J. Moon, L. C. Ha, T. Moehl, R. H. Baker, P. Wang, S. M. Zakeeruddin, M. Gratzel, Nano Lett. 2011, 11, 1452.

[13]. N. Ahn, D. Y. Son, I. H. Jang, S. M. Kang, M. Choi, N. G. Park, J. Am. Chem. Soc. 2015, 137, 8696.

[14]. J. Cao, Y.-M. Liu, X. Jing, J. Yin, J. Li, B. Xu, Y.-Z. Tan, N. Zheng, J. Am. Chem. Soc. 2015, 137, 10914.

[15]. J. Y. Jeng, Y. F. Chiang, M. H. Lee, S. R. Peng, T. F. Guo, P. Chen, T. C. Wen, Adv. Mater. 2013, $25,3727$.

[16]. J. H. Heo, H. J. Han, D. Kim, T. K. Ahn, S. H. Im, Energy Environ. Sci. 2015, 8, 1602.

[17]. W. Y. Chen, L. L. Deng, S. M. Dai, X. Wang, C. B. Tian, X. X. Zhan, S. Y. Xie, R. B. Huang, L. S. Zheng, J. Mater. Chem. A. 2015, 3, 19353.

[18]. Y. Zhang, X. Hu, L. Chen, Z. Huang, Q. Fu, Y. Liu, L. Zhang, Y. Chen, Org. Electron. 2016, 30, 281.

[19]. H. Chen, X. Pan, W. Liu, M. Cai, D. Kou, Z. Huo, X. Fang, S. Dai, Chem. Commun. 2013, 49, 7277.

[20]. S. N. Habisreutinger, T. Leijtens, G. E. Eperon, S. D. Stranks, R. J. Nicholas, H. J. Snaith, Nano Lett. 2014, 14, 5561.

[21]. T. Leijtens, T. Giovenzana, S. N. Habisreutinger, J. S. Tinkham, N. K. Noel, B. A. Kamino, G. Sadoughi, A. Sellinger, H. J. Snaith, ACS Appl. Mater. Interfaces 2016, 8, 5981.

[22]. J. H. Heo, S. H. Im, J. H. Noh, T. N. Mandal, C.S. Lim, J. A. Chang, Y. H. Lee, H. Kim, A. Sarkar, M. K. Nazeeruddin, M. Grätzel, S. I. Seok, Nat. Photonics. 2013, 7, 486.

[23]. W. S. Yang, J. H. Noh, N. J. Jeon, Y. C. Kim, S. Ryu, J. Seo, S. I. Seok, Science. 2015, 348, 1234. [24]. J. H. Heo, H. J. Han, M. Lee, M. Song, D. H. Kim, S. H. Im, Energy Environ. Sci. 2015, 8, 2922. [25]. X. Li, J. Yang, Q. Jiang, W. Chu, D. Zhang, Z. Zhou, J. Xin, ACS Appl. Mater. Interfaces. 2017, 9, 41354. 
[26]. C. Zuo L. Ding, Small, 2015, 11, 5528.

[27]. M. Jung, Y. C. Kim, N. J. Jeon, W. S. Yang, J. Seo, J. H. Noh, S. I. Seok, ChemSusChem. 2016, 9, 2592.

[28]. N. Arora, M. I. Dar, A. Hinderhofer, N. Pellet, F. Schreiber, S. M. Zakeeruddin, M. Gratzel, Science. 2017, 358, 768.

[29]. X. Yin, P. Chen, M. Que, Y. Xing, W. Que, C. Niu, J. Shao, ACS Nano. 2016, 10, 3630.

[30]. I. S. Yang, M. R. Sohn, S. Do Sung, Y. J. Kim, Y. J. Yoo, J. Kim, W. I. Lee, Nano Energy. 2017, $32,414$.

[31]. M. H. Li, J. H. Yum, S. J. Moon, P. Chen, Energies. 2016, 9, 1.

[32]. P. Pattanasattayavong, G. O. N. Ndjawa, K. Zhao, K. W. Chou, N. Yaacobi-Gross, B. C. O. Regan, A. Amassian, T. D. Anthopoulos, Chem. Commun. 2013, 49, 4154.

[33]. B. N. Ezealigo, A. C. Nwanya, A. Simo, R. Bucher, R. U. Osuji, M. Maaza, M. V. Reddy, F. I. Ezema, Arab. J. Chem. 2017.

[34]. P. Qin, S. Tanaka, S. Ito, N. Tetreault, K. Manabe, H. Nishino, M. K. Nazeeruddin, M. Gratzel, Nat. Commun. 2014, 5, 1.

[35]. N. Anttu, ACS Photonics. 2015, 2, 446.

[36]. W. E. I. Sha, X. Ren, L. Chen, W. C. H. Choy, Appl. Phys. Lett. 2015, 106, 1.

[37]. M. Mostefaoui, H. Mazari, S. Khelifi, A. Bouraiou, R. Dabou, Energy Procedia. 2015, 74, 736.

[38]. M. I. Hossain, F. H. Alharbi, N. Tabet, Sol. Energy. 2015, 120, 370.

[39]. K. Tan, P. Lin, G. Wang, Y. Liu, Z. Xu, Y. Lin, Solid. State. Electron. 2016, 126, 75.

[40]. A. Toshniwal, A. Jariwala, V. Kheraj, A. S. Opanasyuk, C. J. Panchal, jnep. 2017, 9, 03038.

[41]. S. Z. Haider, H. Anwar, M. Wang, Semicond. Sci. Technol. 2018, 33, 35001.

[42]. F. Anwar, R. Mahbub, S. S. Satter, S. M. Ullah, Int. J. Photoenergy. 2017, 1.

[43]. V. Pfeifer, P. Erhart, S. Li, K. Rachut, J. Morasch, J. Brötz, P. Reckers, T. Mayer, S. Ruhle, A. Zaban, I. Mora Sero, J. Bisquert, W. Jaegermann, A. Klein, J. Phys. Chem. Lett. 2013, 4, 4182. 
[44]. L. Calio, S. Kazim, M. Gratzel, S. Ahmad, Angew. Chemie - Int. Ed. 2016, 55, 14522.

[45]. N. Wijeyasinghe, A. Regoutz, F. Eisner, T. Du, L. Tsetseris, Y. H. Lin, H. Faber, P. Pattanasattayavong, J. Li, F. Yan, M. A. McLachlan, D. J. Payne, M. Heeney, T. D. Anthopoulos, Adv. Funct. Mater. 2017, 27, 1.

[46]. F. H. Babaei, N. A. Sheini, M. M. Lajvardi, presented at IOP Conf. Ser. Mater. Sci. Eng. Oxygen adsorption at noble metal/ $\mathrm{TiO}_{2}$ junctions, 2016.

[47]. G. Moddel, in Rectenna Sol. Cells, Springer, New York, 2013.

[48]. M. M. Lajvardi M. Jahangiri, IOP Conf. Ser. Mater. Sci. Eng. 2016, 108, 1.

[49]. J. Jeng, Y. Chiang, M. Lee, T. Guo, P. Chen, T. Wen, SPIE Newsroom, 2013, 3.

[50]. S. A. Gavrilov, A. V. Zheleznyakova, A. A. Dronov, T. Dittrich, presented at Physics, Chem. Appl. Nanostructures efficiency enhancement of eta-cells fabricated by silar deposition, 2009.

[51]. G. Boschloo, T. Edvinsson, A. Hagfeldt, in Nanostructured Mater. Sol. Energy Convers., edited by T. Soga, 1st ed. (Elsevier Ltd, 2006).

[52]. C. C. Homes, Science. 2001, 293, 673.

[53]. J. E. Jaffe, T. C. Kaspar, T. C. Droubay, T. Varga, M. E. Bowden, G. J. Exarhos, J. Phys. Chem. C 2010, 114, 9111.

[54]. T. Zhao, W. Shi, J. Xi, D. Wang, Z. Shuai, Sci. Rep. 2016, 7, 1.

[55]. G. Giorgi, J. I. Fujisawa, H. Segawa, K. Yamashita, J. Phys. Chem. Lett. 2013, 4, 4213.

[56]. M. I. Hossain, F. H. Alharbi, N. Tabet, Sol. Energy. 2015, 120, 370.

[57]. Q. Zhang, C. S. Dandeneau, X. Zhou, G. Cao, Adv. Mater. 2009, 21, 4087.

[58]. C. Motta, F. El-Mellouhi, S. Sanvito, Sci. Rep. 2015, 5, 12746.

[59]. P. Pattanasattayavong, V. Promarak, T. D. Anthopoulos, Adv. Electron. Mater. 2017, 3, 1600378.

[60]. H. Wang, Y. Liu, M. Li, H. Huang, H. M. Xu, R. J. Hong, H. Shen, Optoelectron. Adv. Mater. Rapid Commun. 2010, 4, 1166.

[61]. S. Ito, S. Tanaka, H. Nishino, J. Phys. Chem. Lett. 2015, 6, 881. 
[62]. S. Ito, S. Tanaka, H. Nishino, Chem. Lett. 2015, 44, 849.

[63]. W. Peng, J. Yin, K. T. Ho, O. Ouellette, M. De Bastiani, B. Murali, O. El Tall, C. Shen, X. Miao, J. Pan, E. Alarousu, J.H. He, B. S. Ooi, O. F. Mohammed, E. Sargent, O. M. Bakr, Nano Lett. 2017, 17, 4759 .

[64]. K.-G. Lim, S. Ahn, H. Kim, M.-R. Choi, D. H. Huh, T.-W. Lee, Adv. Mater. Interfaces. 2016, 3, 1500678.

[65]. L. A. Frolova, N. N. Dremova, P. A. Troshin, Chem. Commun. 2015, 51, 14917.

[66]. C.-S. Jiang, M. Yang, Y. Zhou, B. To, S. U. Nanayakkara, J. M. Luther, W. Zhou, J. J. Berry, J. van de Lagemaat, N. P. Padture, K. Zhu, M. M. Al-Jassim, Nat. Commun. 2015, 6, 8397.

[67]. S. Dong, Y. Liu, Z. Hong, E. Yao, P. Sun, L. Meng, Y. Lin, J. Huang, G. Li, Y. Yang, Nano Lett. 2017, 17, 5140 .

[68]. H. Kim, K.-G. Lim, T.-W. Lee, Energy Environ. Sci. 2016, 9, 12.

[69]. M. R. Ahmadian-Yazdi, F. Zabihi, M. Habibi, M. Eslamian, Nanoscale Res. Lett. 2016, 11, 408.

[70]. J. Barbe, M. L. Tietze, M. Neophytou, B. Murali, E. Alarousu, A. El Labban, M. Abulikemu, W. Yue, O. F. Mohammed, I. McCulloch, A. Amassian, and S. Del Gobbo, ACS Appl. Mater. Interfaces. 2017, 9, 11828.

[71]. M. B. Johnston and L. M. Herz, Acc. Chem. Res. 2016, 49, 146.

[72]. Y. Zhou and G. Long, J. Phys. Chem. C. 2017, 121, 1455.

[73]. R. B. K. Siram, J. Das, S. Mukhopadhyay, T. M. Brenner, N. Kedem, M. Kulbak, T. Bendikov, D. Cahen, G. Hodes, and B. Rybtchinski, Adv. Mater. Interfaces, 2016, 3, 1600506.

[74]. J. Shi, X. Xu, D. Li, and Q. Meng, Small, 2015, 11, 2472.

[75]. Y. S. Zhu Z1, Ma J, Wang Z, Mu C, Fan Z, Du L, Bai Y, Fan L, Yan H, Phillips DL, J Am Chem Soc. 2014, 136, 3760 .

[76]. A. Abrusci, S. D. Stranks, P. Docampo, H.-L. Yip, A. K.-Y. Jen, H. J. Snaith, Nano Lett. 2013, 13, 3124. 
[77]. Y. Xiao, G. Han, Y. Li, M. Li, J. Wu, J. Mater. Chem. A, 2014, 2, 16856.

[78]. W. Yang, Y. Yao, C.-Q. Wu, J. Appl. Phys. 2015, 117, 155504.

[79]. H. Wang, P. Amsalem, G. Heimel, I. Salzmann, N. Koch, M. Oehzelt, Adv. Mater. 2014, 26, 925.

[80]. Q. K. Wang, R. B. Wang, P. F. Shen, C. Li, Y. Q. Li, L. J. Liu, S. Duhm, J. X. Tang, Adv. Mater. Interfaces. 2015, 2, 1400528.

[81]. K. G. Lim, S. Ahn, Y. H. Kim, Y. Qi, T. W. Lee, Energy Environ. Sci. 2016, 9, 932.

[82]. V. E. Madhavan, I. Zimmermann, C. Roldán-Carmona, G. Grancini, M. Buffiere, A. Belaidi, M. K. Nazeeruddin, ACS Energy Lett. 2016, 1, 1112. 


\section{List of Figures}

Figure 2. a) Schematic representation of the device structure b) Band diagram of the $\mathrm{TiO}_{2} / \mathrm{CH}_{3} \mathrm{NH}_{3} \mathrm{PbI}_{3} / \mathrm{CuSCN}$ / $\mathrm{Au}$

Figure 2. Band alignments of absorber/IDL2/HTM layers with a) negative and b) positive VBO. IDL2 is used to count the recombination at the interface.

Figure 3. Band alignments of ETM/IDL1/absorber layers with a) negative and b) positive CBO. IDL1 is used to count the recombination at the interface.

Figure 4. a) J-V curves and b) Quantum efficiency curves of PSC with parameters in Table 2 after device optimization.

Figure 5. Effect of $\mathrm{N}_{\mathrm{A}}$ of absorber layer on a) performance parameters b) quantum efficiency of PSC

Figure 6. a) The quasi-Fermi level splitting in the absorber layer with pristine $\mathrm{TiO}_{2}$ and pristine $\mathrm{CuSCN}$ at open circuit condition b) Distribution of quasi fermi level of hole for different values of $\mathrm{N}_{\mathrm{A}}$ of absorber

Figure 7. Effect of thickness of absorber layer on a) performance parameters and b) quantum efficiency of PSC

Figure 8. Effect of diffusion lengths and $\mathrm{N}_{\mathrm{t}}$ of absorber layer on performance parameters of PSC

Figure 9. Effect of $\mathrm{Nt}$ on $\mathrm{J}-\mathrm{V}$ curve for a) ETM/absorber interface b) absorber/HTM interface c) Variation in performance parameters with different $\mathrm{N}_{\mathrm{t}}$ at interfaces

Figure 10. Graphic representation of energy level arrangements at absorber/HTM interface. a) High level and low level VBM of HTM and absorber respectively, Type I staggered band gap b) small band gap of HTM in contact with large band gap of absorber, Type II straddling band gap c) Deep level and high level lying of VBM of HTM and absorber respectively, Type III reverse staggered band gap d) Large band gap of HTM in contact with small band gap of absorber, Type IV reverse straddling band gap

Figure 11. Effect of (a) different VBO at absorber/ HTM interface (b) different CBO at ETM/absorber interface on performance parameters of PSC. 


\section{Table of content}

\section{Theoretical Optimization to Design Efficient Perovskite Solar Cell}

Syed Zulqarnain Haider, Hafeez Anwar* and Mingqing Wang

Theoretical optimization to design efficient perovskite solar cell by using $\mathrm{CuSCN}$ as inorganic hole transport material (HTM). It is found that defect density of the absorber, ETM/absorber and absorber/HTM interface influences the performance of PSC appreciably. The PCE is found to be 21.94 $\%$ upon optimization of the defect density leading towards the low recombination rate and better transport of charge carriers thorough absorber and interfaces. Upon final optimization, PCE of $25.02 \%$ is achieved.

Keywords: Theoretical optimization, CuSCN, Defect density, Hole transport material
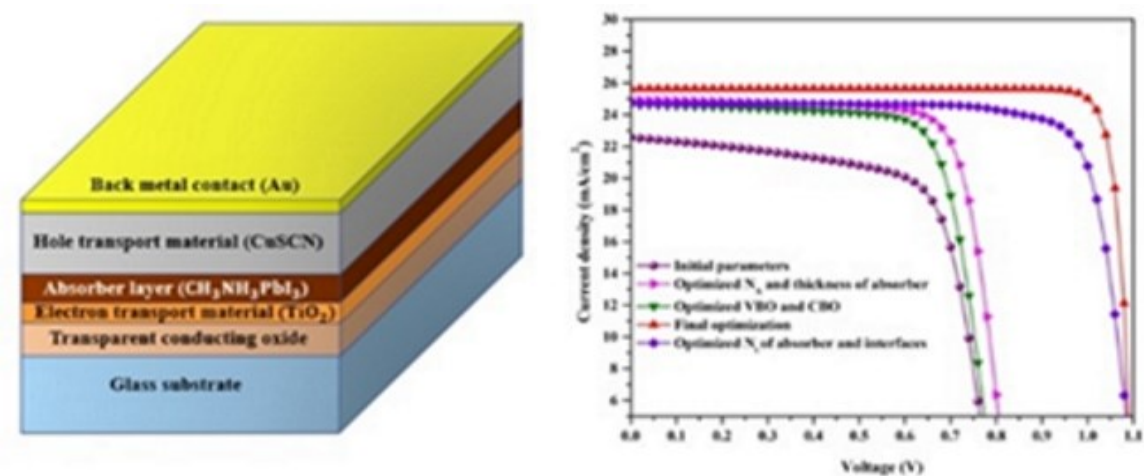